Int. J. Dev. Biol. 48: 47-55 (2004)

Technical Article

\title{
A P19CI6 GFP reporter line to quantify cardiomyocyte differentiation of stem cells
}

\author{
JENNIFER C. MOORE ${ }^{1}$, RENE SPIJKER ${ }^{1}$, ANTON C. MARTENS ${ }^{2}$, TEUN DE BOER ${ }^{1,3}$, MARTIN B. ROOK ${ }^{3}$, MARCEL \\ A.G. VAN DER HEYDEN ${ }^{3}$, LEON G. TERTOOLEN ${ }^{1}$ and CHRISTINE L. MUMMERY*,1 \\ Hubrecht Laboratory ${ }^{1}$, Dept. of Hematology ${ }^{2}$ and Dept. Medical Physiology ${ }^{3}$, University Medical Center, Utrecht, The Netherlands
}

\begin{abstract}
The clinical application of stem cell therapies is still limited by the ability to produce defined, differentiated cell populations in large numbers in culture. High throughput screens to identify factors which enhance differentiation to particular lineages and promote expansion of precursors in culture are dependent on the development of sensitive and reproducible assays for screening. Here we describe a bioassay to identify factors with cardiomyogenic activity which enhance the yield of cardiomyocytes from undifferentiated stem cells. The assay is based on a Green Fluorescent Protein (GFP) reporter under the transcriptional control of the $250 \mathrm{bp}$ MLC-2v promoter expressed in pluripotent P19 embryonal carcinoma cells. We show that reporter expression is limited to developing cardiomyocytes and can be used to determine quantitatively the number of ventricular cardiomyocytes formed in cultures under inducing or non-inducing conditions. This assay differs from all others described previously in that it has an easily quantifiable readout, there is negligible background differentiation in the absence of exogenous cardiogenic factors and it is carried out feeder cell-free. Thus, it is entirely independent of competing differentiation inhibitory factors, such as leukemia inhibitory factor. Patch clamp electrophysiology of the GFP-positive cells confirmed their functional ventricular phenotype and indicated that selection on the basis of GFP would provide cells suitable for transplantation.
\end{abstract}

KEY WORDS: P19Clone6, cardiac differentiation, embryonal carcinoma cell

\section{Introduction}

Since the initial derivation and characterization of human embryonic stem cells much research has focused on assessing their potential to heal and regenerate damaged tissues (Thomson etal., 1998; Reubinoff et al., 2000; Gepstein, 2002). Understanding the signal transduction pathways that result in formation of mature heart cells from an undifferentiated epiblast during development is crucial to progress in finding new stem cell therapies for treatment of heart disease. Among these, the transplantation of ventricular cardiomyocytes derived from human stem cells into hearts damaged by myocardial infarction has been an area of particular interest (Passier and Mummery, 2003). The biggest roadblock to such therapies are the current inability to quantify the effectiveness of factors with putative cardiomyogenic potential and the difficulty in selecting pure or nearly pure population of cardiomyocytes without destroying the cells (Mummery et al., 2003; Xu et al., 2002; Anisimov et al., 2002). Here we describe a quantitative assay that is designed to i) select for ventricular cardiomyocytes, ii) screen for and identify novel factors with enhanced cardiomyogenic activity, and iii) test the effectiveness of novel and "known" cardiomyogenic factors, such as wnts and BMPs, for their ability to stimulate cardiomyogenic differentiation of stem cells in culture.

The undifferentiated growth of P19 embryonal carcinoma (EC) cells is feeder cell independent, they divide rapidly in culture, and are pluripotent, making them an excellent model system for developing stem cells bioassays (reviewed in van der Heyden and Defize, 2003). P19 EC cells were first derived by Rogers et al. (1982), from a teratocarcinoma formed when a 7.5 day old embryo was transplanted into the testis of an isogenic acceptor mouse (McBurney and Rogers, 1982). Stem cells were isolated from the resulting tumor and clonally cultured to select for cells that maintained their undifferentiated phenotype (McBurney and Rogers, 1982). Later studies showed that these cells were indeed pluripotent, giving rise to tissues of all three germ layers (Rossant and McBurney, 1982). P19 EC cells grown as aggregates in suspen-

Abbreviations used in this paper: bp, base pair; CM, conditioned medium; cmv, cytomegalovirus; EC, embryonal carcinoma; GFP, green fluorescent protein.

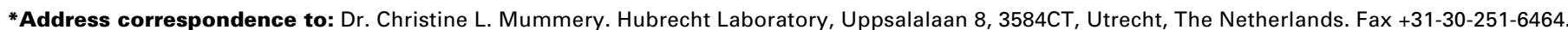
e-mail: christin@niob.knaw.nl
} 
sion in the presence of DMSO (1\%) lead to the formation of mesoderm lineages, including cardiomyocytes (Jones-Villeneuve et al., 1982; Edwards et al., 1983). A concentration dependent retinoic acid response has also been described, where retinoic acid concentrations of $10^{-7} \mathrm{M}$, cause P19 EC cells to differentiate to endoderm; at $10^{-8} \mathrm{M}$, neuronal cells form; and finally at $10^{-9} \mathrm{M}$, mesodermal differentiation occurs (McBurney et al., 1982; Mummery et al., 1991; Jones-Villeneuve et al., 1982)

Recently a new sub clone of P19 EC cells (called P19Clone6) was described (Habara-Ohkubo, 1996). This clone was isolated from P19 EC cells aggregated in the presence of $1 \mathrm{nM}$ retinoic acid and plated 3 days later. After culturing for 6 months the remaining undifferentiated cells were cloned by limiting dilution (HabaraOhkubo, 1996). This new cell line differs from the 'mother' clone in that it can be differentiated to cardiomyocytes in monolayer culture in response to DMSO without a separate step for aggregation being necessary, although local high densities are required (HabaraOhkubo, 1996). We have also found that this clone does not spontaneously differentiate to cardiomyocytes following aggregation in the presence of fetal calf serum, as had been observed in the original P19 cell line (Mummery etal., 1991) but that DMSO or other cardiogenic factors are strictly necessary. These characteristics give $\mathrm{P} 19 \mathrm{Clone} 6$ cells a distinct advantage above either uncloned P19 EC cells or pluripotent mouse ES cells as a basis for developing a bioassay.

In order to develop an assay with an easily detectable read-out in live cells, that is specific to heart tissue and is detectable early in differentiation, GFP under the transcriptional control of the MLC$2 v$ promoter was used. Myosin proteins, which are composed of 2 myosin heavy chains and two myosin light chains, are the major component of the contractile part of a muscle cell (Adelstein and Eisenberg, 1980; Emerson, Jr. and Bernstein, 1987). The myosin light chains are divided into two categories - the alkali light chains or MLC-1 genes and the regulatory light chains or MLC-2 (Barton and Buckingham, 1985). The rat MLC-2v gene consists of 7 exons and a promoter region of approximately $2.7 \mathrm{~kb}$ (Henderson et al., 1989). MLC-2v is expressed exclusively in the ventricle of the rat and mouse hearts in adults and during embryogenesis (Lee et al., 1992; O'Brien et al., 1993). Work by many groups has shown that the 250 bp region immediately $5^{\prime}$ of the translation start site is sufficient to confer heart specific expression in vitro and in vivo
A

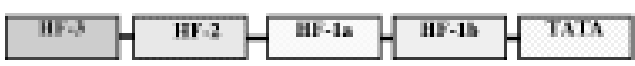

B

\section{MLC-2v 250bp Promoter}

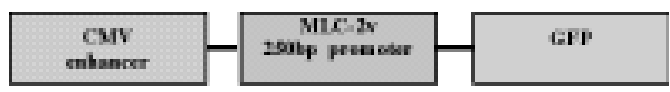

\section{Reporter Construct}

Fig. 1. The 250 bp MLC-2v promoter and the $\mathrm{CMV}_{\text {enh }} / \mathrm{MLC}-2 \mathrm{v} / \mathrm{GFP}$ construct. (A) The MLC-2v 250 bp promoter consists of 5 domains - HF3, HF-2, HF-1a, HF-1b and the TATA box. (B) The reporter construct described here consists of GFP under the control of the MLC-2v $250 \mathrm{bp}$ promoter that is preceded by the enhancer portion (406 bp) of the human CMV immediate early promoter.

(Henderson et al., 1989; Lee et al., 1992). Here we report the characterization of a P19Clone6 reporter cell line expressing GFP under the transcriptional control of the rat MLC-2v 250 bp promoter and demonstrate that it can be used to quantitate the number of cardiomyocytes in a given differentiation assay. Although similar stable mouse ES cell lines have been generated (using the MLC$2 v$ promoter and others), these are not suitable for a large scale screen due to the high rate of spontaneous differentiation to cardiomyocytes as soon as the cells form aggregates in suspension (embryoid bodies) (Müller et al., 2000; Kolossov et al., 1998; Wobus etal., 1997). We demonstrate the use of these reporter cells in screening for novel cardiomyogenic factors and in determining the effect of known inducers quantitatively.

\section{Results}

\section{Stable EC cell lines expressing GFP in cardiomyocytes}

A 250 bp fragment of the MLC-2v promoter containing the HF3, HF-2, HF-1a and HF-1b motifs (Fig. 1A), which had previously been reported to be the minimal promoter sequence for MLC-2v, was cloned into the promoter-less pEGFP-N2 vector from Clontech (Henderson et al., 1989; Lee et al., 1992; Ross et al., 1996). Initial experiments with this construct resulted in no detectable GFP in P19Clone6 cells induced to differentiate into beating cardiomyocytes. In an attempt to enhance the GFP signal, a 406 bp region of the human cytomegalovirus (CMV) immediate early
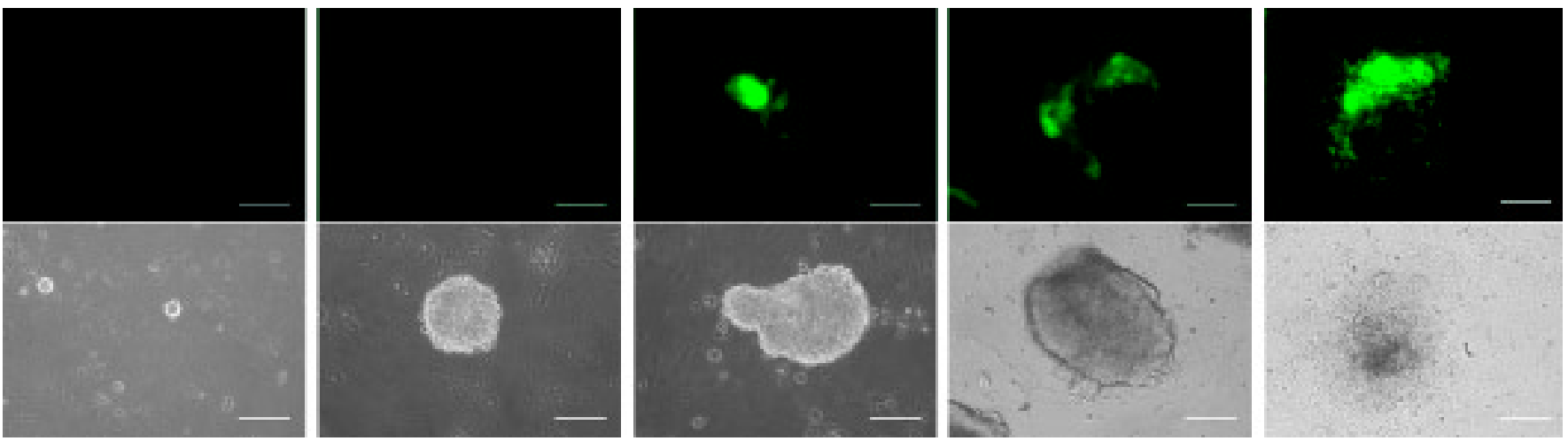

Fig. 2. GFP reporter expression in P19CI6 cells co-cultured with END2 cells. P19Cl6 reporter cells were plated at a density of 130 cells/cm ${ }^{2}$ on END2 cells and grown for 10 days. MLC-2v GFP reporter activity is shown in Panels A through E on days 2, 4, 6, 8 and 10, respectively. No GFP expression was detectable in the first four days (A,B). On day 6, GFP expression was first detectable (C) and increased until day 10 (D,E). During this time, areas of beating muscle were first visible. There was no increase of beating areas or GFP expression after day 10. Scale bars, $500 \mu \mathrm{M}$. 
A
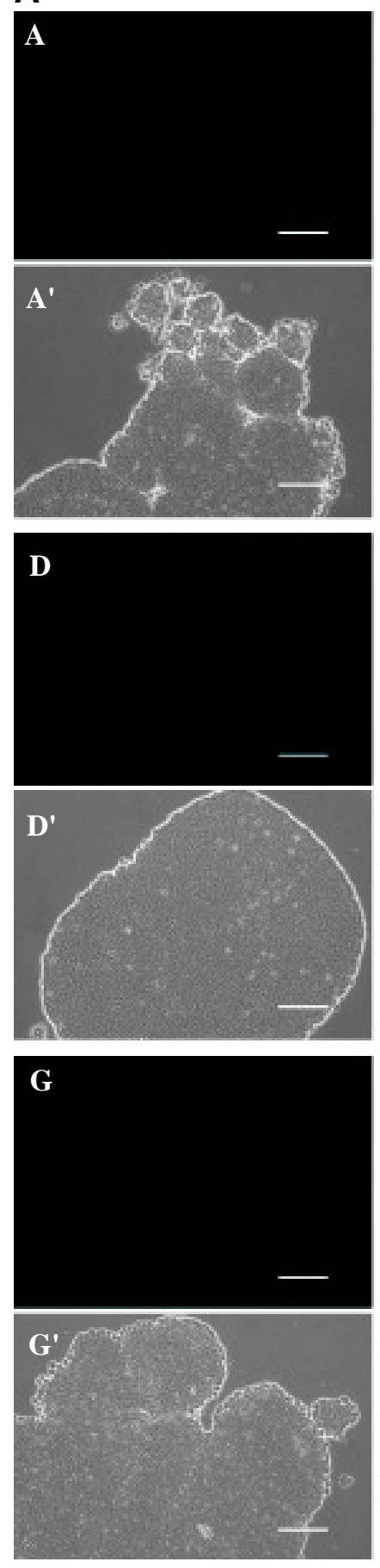
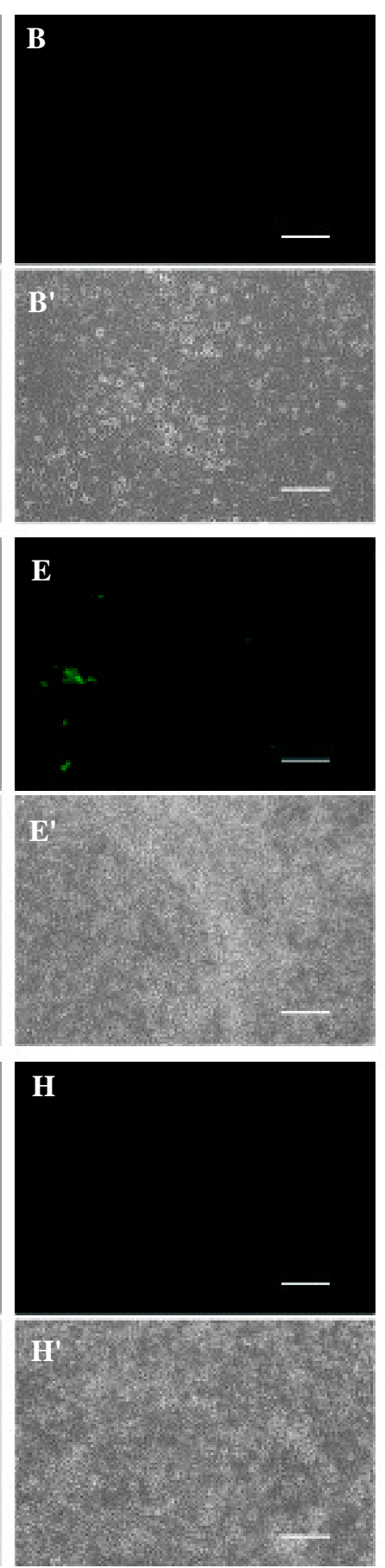
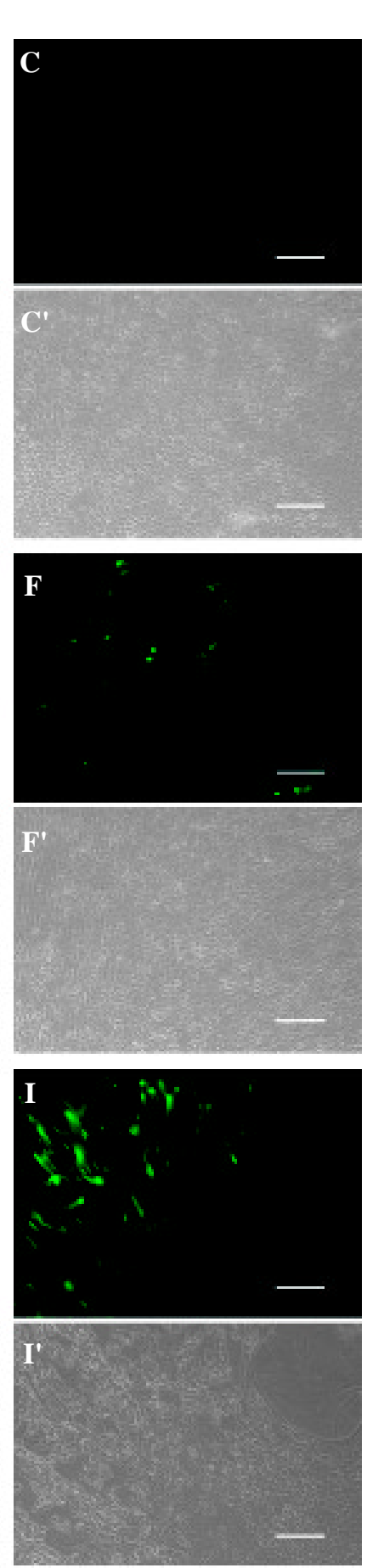

B

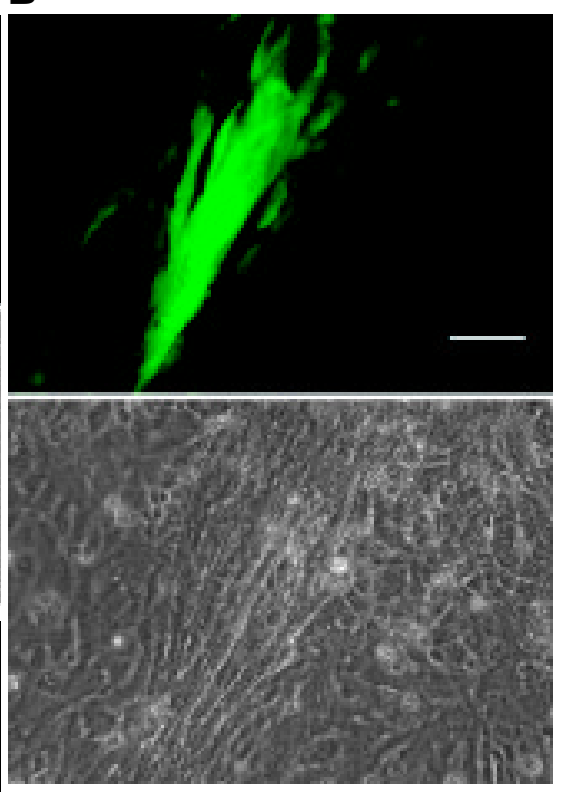

Fig. 3. GFP reporter expression in $\mathrm{P} 19 \mathrm{Cl} 6$ cell aggregates. (A) 800 P19C/6 GFP reporter cells were aggregated in the presence of normal growth media alone (Panels A-C), growth media containing $1 \%$ DMSO (Panels $D-F)$ and 25\% growth media / 75\% END2 conditioned media (Panels G-I). No visible GFP expression was observed in any of the cells on day 2 (Panels A, D and G). GFP was first visible on day 4 in cells aggregated in the presence of DMSO (Panel E) and on day 6 in cells aggregated in the presence of either 1\% DMSO (Panel F) or 75\% END2 CM (Panel I). GFP positive cells were never seen in cells aggregated in the presence of growth media alone. Scale bar is $200 \mu \mathrm{M}$. (B) A $20 \mathrm{X}$ magnification of beating muscle expressing GFP. Scale bar, $100 \mu \mathrm{M}$. promoter was sub-cloned in front of the 250bp MLC-2v promoter (Fig. 1B). The $\mathrm{CMV}_{\text {enh }} / \mathrm{MLC}-2 \mathrm{v} / \mathrm{GFP}$ construct was then stably transfected into P19Clone6 cells. Stable clonal lines (antibiotic resistant) were selected and induced to differentiate and screened to find a line that expressed high levels of GFP in cardiomyocytes only. Although most clones expressed GFP specifically in beating areas, one clone (designated \#1-23) was identified as a stable line that had the highest level of GFP expression that appeared to be restricted to areas of beating muscle (see Fig. 3C, below) and was used in all of the subsequent experiments.

\section{GFP is expressed at high levels in P19Clone6 cell derived cardiomyocytes}

END2 and clone \#1-23 cells were co-cultured to obtain beating muscle as described previously (Mummery et al., 1991). These cocultures were examined over time by epifluorescence microscopy to determine the levels and specificity of GFP expression qualitatively. During the first 3 days of co-culture, the P19EC clone \#1-23 cells aggregated in the medium and did not attach to the END2 cells. During this time, there was no GFP expression in the cells (Fig. 2, Panel A). By the fourth day, aggregates of P19Clone6 cells 
had attached to the END2 cells, but there was still no specific GFP expression (Fig. 2, Panel B). By day 6, GFP expression was readily detectable in specific cells, although there were usually still no areas of beating muscle (Fig. 2, Panel C). By eight days after the start of the co-culture, GFP was expressed in many cells and this expression corresponded to areas of beating muscle (Fig. 2, Panel D. There was no increase in either beating muscle or GFP expression after day 10 (Fig. 2, Panel E).

The GFP P19Clone6 reporter cell line was also tested in response to aggregation in the presence of DMSO or END2 conditioned media. As observed in the co-cultures, P19Clone6 cells express no GFP before aggregation (data not shown). After aggregation for 2 days there were no differences in GFP expression between control cells and cells aggregated in the presence of DMSO, or END2 CM (Fig. $3 A$, Panels $A, D, G)$. However, after four days of aggregation in the presence of DMSO there was detectable GFP expression (Fig. 3A, Panel $E)$, although the aggregates incubated in the presence of END2 CM and control media still had no GFP expression (Fig. 3A,
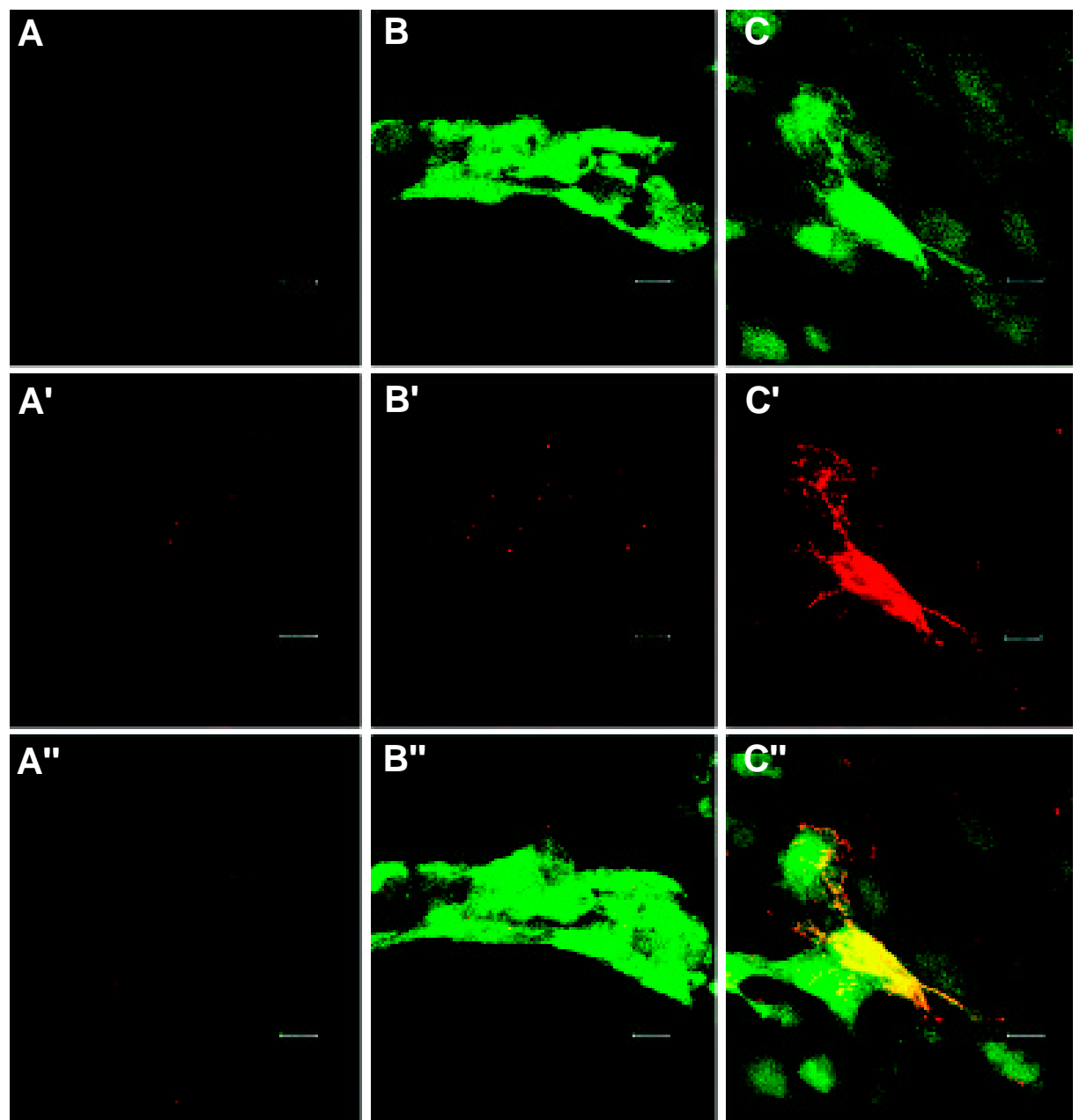

Fig. 4. GFP positive cells are also positive for other cardiac markers. Cells aggregated in the presence of END2 CM were stained with anti- $\alpha$-alpha actinin $\left(\mathbf{A}^{\prime}-\mathbf{C}^{\prime}\right)$ and photographed by confocal microscopy. The same cells were also visualized for GFP expression (A-C) and the merge of these images is shown in (A"- $\left.\mathbf{C}^{\prime \prime}\right)$. In undifferentiated cells (Day 0), neither GFP (A) nor alpha actinin expression (A') was observed. By day 5 (1 day after plating), GFP expression was detectable (B), but

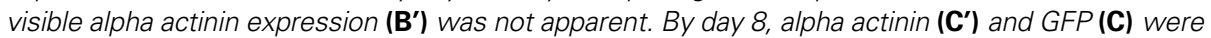
both expressed and co-localized to the same cells. Scale bar, $8 \mu \mathrm{M}$.
Panels $\mathrm{B}, \mathrm{H})$. On day 4 the aggregates were plated and allowed to grow for another 2-6 days or until beating muscle was visible. By day 2 after plating (day 6), beating muscle was present in cells aggregated in the presence of DMSO and END2 CM and both types of aggregates now showed considerable increases in the levels of GFP expression (Fig. 3A, Panels F,I), while cells in the media showed no GFP expression (Fig. 3A, Panel C). An area of beating muscle from an aggregate 4 days after plating (day

\section{GFP positive cells express other cardiac markers}

To verify that the differentiated cells expressing GFP were indeed cardiomyocytes, cells at various stages of differentiation were fixed, stained and examined for the co-expression of GFP and the cardiac marker $\alpha$-actinin. As shown in Fig. 4, the undiffercells contained neither GFP (Fig. 4, panel A) nor $\alpha$-actinin (Fig. 4, Panel A'), the embryoid bodies at day 5 contained some B) and no $\alpha$-actinin (Fig. 4, Panel B') and the beating muscle cells at day 8 contained GFP (Fig. 4, Panel C) and $\alpha$-actinin (Fig. 4, Panel C'). This suggests that GFP is expressed specifically in cardiomyocytes.

\section{GFPexpression is increased quantitatively in induced vs. non-induced cultures}

As described in above, P19Clone6 \#1-23 stable transfectants were aggregated in the presence of END2 conditioned medium, 1\% DMSO or normal growth media. After 4 days the aggregates were plated and incubated in the presence of normal growth media for 4 days. The aggregates were then trypsinized to form a single cell suspension and GFP expression was quantified by FACS analysis FACS analysis showed that in the cultures aggregated in the presence of END2 conditioned medium $12.4 \pm 4.8 \%$ of cells were expressing GFP above the threshold level $(p \leq 0.005)$ (Fig. 5A). In cultures aggregated in the presence of $1 \%$ DMSO, $25.7 \pm 9.1 \%$ of cells were expressing GFP ( $\leq 0.001)$ (Fig. $5 A)$. In cultures not induced to form beating muscle, only $1.5 \pm 0.8 \%$ of the cells expressed GFP at a level higher than background (Fig. $5 A$ ). Prior to FACS analysis the cells described above were illuminated under fluorescent light and photographed (Fig. 5B). As shown by FACS analysis, the amount of GFP as detected microscopically is also highest in the cells aggregated in the presence of DMSO and lowest in the control cells incubated in the presence of growth media alone (Fig. 5B).

\section{The majority of GFP expressing cells also express the cardiac specific marker tropomyosin}

As described above, cultures of clone \#123 aggregated in the presence of END2 CM and growth media alone were also stained 
A

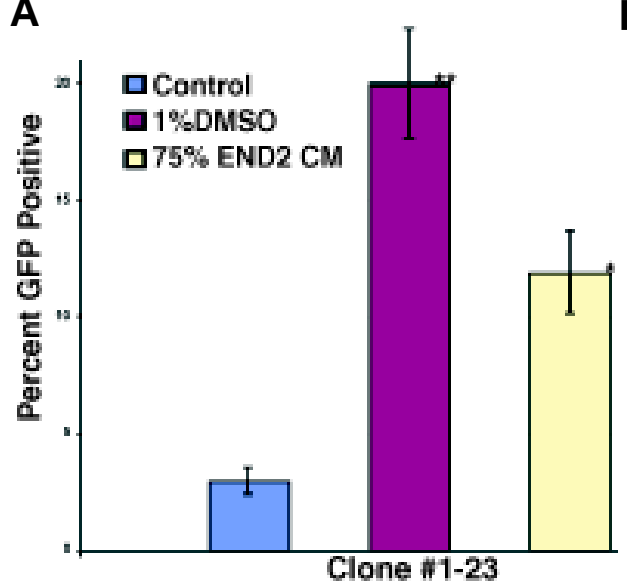

B

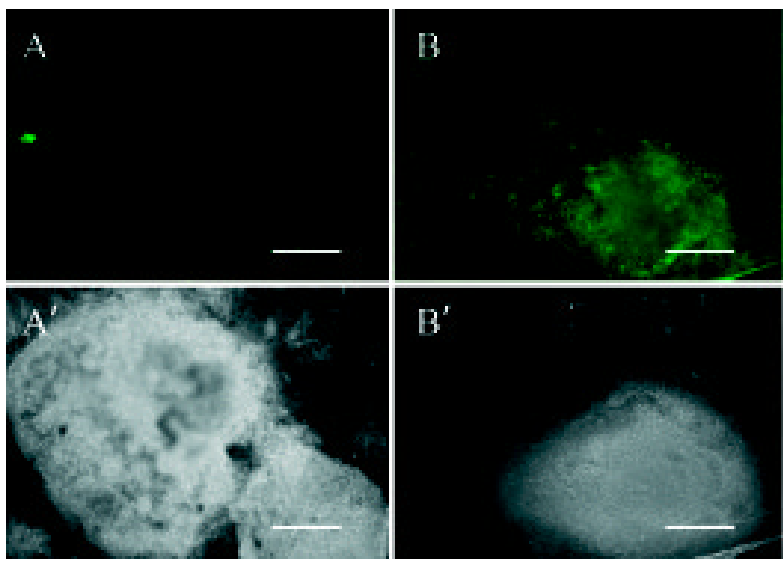

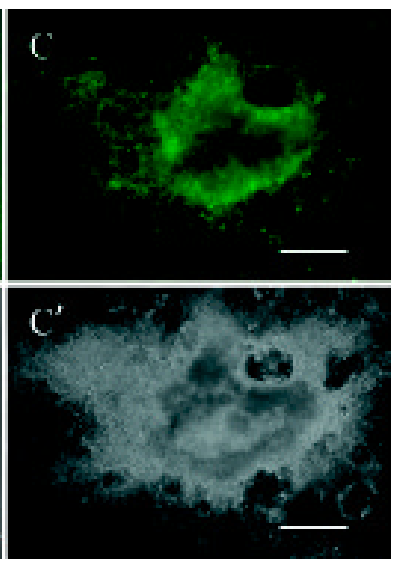

Fig. 5. FACS analysis of GFP reporter expression in P19CI6 derived cardiomyocytes. (A) The percentage of GFP positive reporter cells was determined by FACS analysis. Cells aggregated in the presence of END2 CM (blue bar) or DMSO (pink bar) had significantly more cells expressing GFP than those aggregated in the presence of growth media alone (yellow bar) ( $p \leq 0.005$ and 0.001 , respectively). (B) Fluorescence images were taken of the same colonies after 8 days and show visible GFP expression similar to the results seen by FACS analysis. (A) shows cells grown in growth media alone ( 2\% of the cells are positive). (B) shows cells aggregated in 1\% DMSO ( 19\% of the cells are positive). (C) shows cells aggregated in the presence of $75 \%$ END2 CM ( 13\% of the cells are positive). Scale bar, $500 \mu \mathrm{M}$.

with $\alpha$-tropomyosin, a cardiac muscle marker, and tropomyosin expression levels were quantified by FACS analysis. As expected undifferentiated cells expressed very little GFP or tropomyosin as measured by FACS analysis (Fig. 6A). However, when cells induced to form beating muscle were examined there was a clear shift in the population of cells expressing GFP and tropomyosin. The percentage of cells expressing GFP increased from $2.0 \pm 1.4 \%$ to $33.0 \pm 1.3 \%$. In the same aggregates, tropomyosin expression is increased from $13.0 \pm 11.3 \%$ to $71.2 \pm 4.9 \%$. Importantly, in the induced cells, only about $5.8 \pm 1.0 \%$ expressed GFP without expressing tropomyosin. This means that the majority of the GFP expression is restricted to cardiomyocytes. These values are shown graphically in Fig. 6B.

\section{Electrophysiological characterization}

Preliminary electrophysiological data showed that cardiomyocytes from P19Clone6 cells and the reporter lines derived from them had relatively low maximal diastolic membrane potentials and frequently exhibited spontaneous nodal like action potentials (Fig. 7 A,B) as published recently for cardiomyocytes derived from uncloned P19 EC cells (van der Heyden et al., 2003). Increasing the membrane potential in P19Clone6 \#1-23 derived cardiomyocytes to values around $-80 \mathrm{mV}$ by injecting a constant hyperpolarizing current rendered the cells quiescent. They could then be stimulated with short (100-200 pA) depolarizing current pulses to fire action potentials (Fig. 7C). Stimulated action potentials had amplitudes over $100 \mathrm{mV}$, upstroke velocities $\left(\mathrm{dV} / \mathrm{dt}_{\max }\right)$ of 85-110 V/s and a duration of 6-7 ms at half maximal amplitude $\left(A P D_{50}\right)$. These action potential parameters approach those found in adult mouse ventricular myocytes (Table 1) and suggest that the P19Clone6 \#1-23 derived cardiomyocytes, expressing GFP, display a more adult ventricular electrophysiological phenotype than observed previously in cardiomyocytes from the regular uncloned P19EC cells.

Voltage clamp experiments demonstrated the presence of inward $\mathrm{Na}^{+}$- and $\mathrm{Ca}^{2+}$-currents and outward $\mathrm{K}^{+}$currents (Fig. 7D) at holding potentials close to or more negative than the observed maximal diastolic potential of the cells. However, no inward rectifying potassium current $\left(I_{K_{1}}\right)$ could be detected, explaining the low membrane potentials of the cells. At a holding potential of $-80 \mathrm{mV}$, fast activating and inactivating currents larger than $3 \mathrm{nA}$ (current density of $>150 \mathrm{pA} / \mathrm{pF}$ when normalized to cell size) could be elicited, suggesting efficient expression of cardiac $\mathrm{Na}^{+}$channels (Fig. 7E). Overall, these data confirm the ventricular phenotype of the GFP positive cells derived from P19Clone6 \#1-23.

TABLE 1

\section{ACTION POTENTIAL PARAMETERS}

\begin{tabular}{|c|c|c|c|c|c|c|}
\hline & P19C & & & P19S18 ${ }^{a}$ & & Iult ventricular \\
\hline & Spon & taneous & Triggered & Spontaneous & Triggered & myocyte $^{b}$ \\
\hline $\mathrm{dV} / \mathrm{dt}_{\max }(\mathrm{V} / \mathrm{s})$ & & $10-11$ & $85-110$ & $10-13$ & 39 & 221 \\
\hline $\mathrm{APD}_{50}(\mathrm{~ms})$ & & 23 & $6-7$ & $56-108$ & 53 & 10 \\
\hline MDP or RMP & $(\mathrm{mV})$ & $\sim 54$ & $\sim 80$ & $\sim 50$ & $\sim 80$ & $\sim 81$ \\
\hline
\end{tabular}

$\mathrm{dV} / \mathrm{dt}_{\text {max }}$, maximal upstroke velocity; MDP, maximal diastolic potential; RMP, resting membrane potential; $\mathrm{APD}_{50}$, action potential duration at half maximal amplitude. a, (van der Heyden et al., 2003); b, (Wang et al., 1996).

\section{Discussion}

Most previous studies involving in vitro differentiation of EC or ES cells into cardiomyocytes have had to rely on counting areas of beating muscle or cell destructive methods such as PCR or western blots, to determine the efficiency of differentiation (Paquin et al., 2002; Skerjanc et al., 1998). Developing a high throughput, noninvasive method for quantification of cardiomyocytes in mixed cell populations provides the opportunity to screen for previously unknown cardiomyogenic factors and test combinations of known factors. The properties required of a reporter cell line suitable for the bioassay described above include easy detection in live cells, 
A

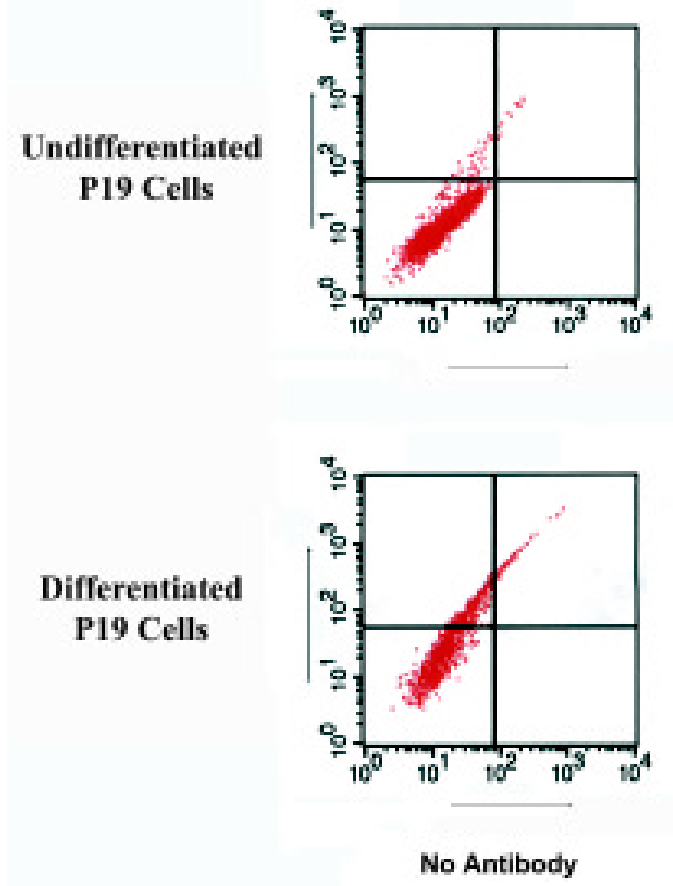

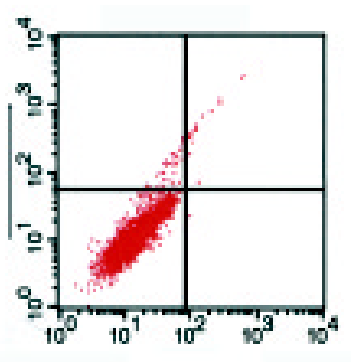
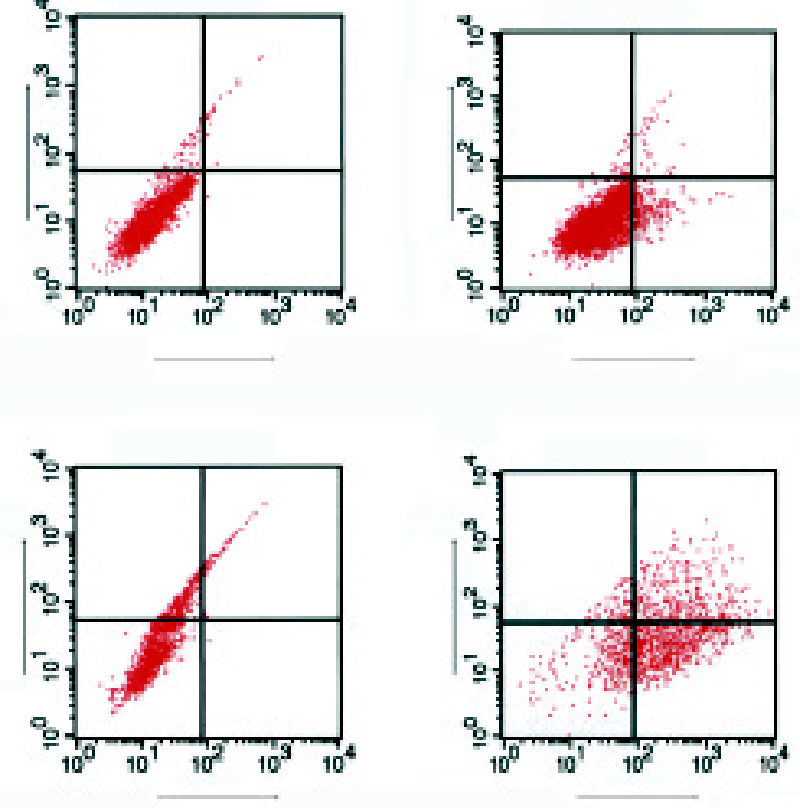

Secondary Antibody Only

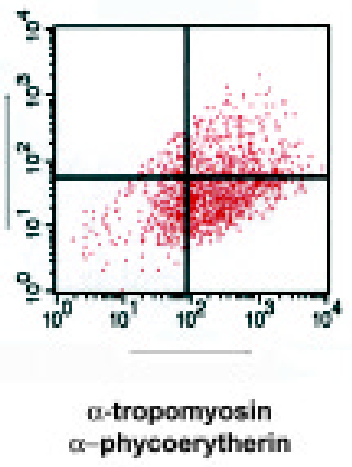

B

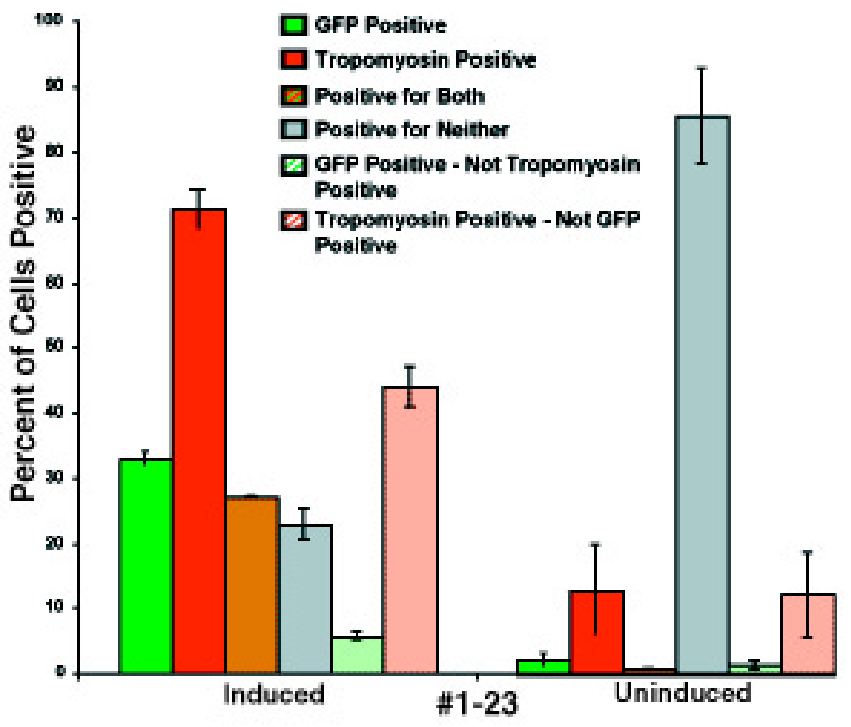

reporter activity limited to cardiomyocytes and reporter activity as early as possible in cardiomyocyte differentiation. Additionally, the same reporter line allows for the selection of nearly pure population of ventricular cardiomyocytes by FACS in a way that does not damage cells, which will be of value for further transplantation experiments. The green fluorescent protein under the transcriptional control of the $\mathrm{CMV}_{\text {enh }} / 250 \mathrm{bp} \mathrm{MLC-2v}$ promoter was chosen as the candidate that would best fulfill all of the above conditions. Cardiac specific reporter lines have been described before (Kolossov et al., 1998; Meyer et al., 2000). However these lines were generated in mouse ES cells that require LIF to remain undifferentiated in mono-
Fig. 6. Tropomyosin is expressed in most GFP-positive cells. (A) Undifferentiated P19Cl6 reporter cells laggregated in the presence of growth medium) have very little GFP (ordinate) or tropomyosin (abscissa) expression (top panel). However, P19Cl6 reporter cells induced to form beating muscle by aggregation in the presence of END2 CM expressed significantly higher amounts of GFP and tropomyosin. Additionally, the majority of cells expressing GFP also expressed tropomyosin. (B) A graphical representation of the FACS data shows that in cultures induced to form cardiomyocytes, less than $6 \%$ of GFP positive cells are tropomyosin negative, and that both GFP and tropomyosin expression was significantly up-regulated in P19Cl6 reporter cells induced to form cardiomyocytes.

layer culture but do not form cardiomyocytes in its absence and have a high rate of spontaneous differentiation to cardiomyocytes as soon as they form embryoid bodies. They are thus unsuitable for screening assays to identify novel cardiogenic factors which require low background, high sensitivity and high specificity. P19Clone6 \#1-23 cells as described here meet these criteria. Previous work has shown that MLC-2v expression is restricted to cardiac cells. Lee et al. have reported that high levels of $250 \mathrm{bp} \mathrm{MLC-2v} \mathrm{promoter} \mathrm{reporter} \mathrm{activity}$ is found in the cardiomyocytes of transgenic mice, while very low levels of the same reporter construct are found in the skeletal muscle cells of these mice (Lee etal., 1992). We first tried a reporter construct consisting of the $250 \mathrm{bp} \mathrm{MLC-2v}$ promoter alone (without the CMV enhancer), but found that there was no detectable GFP signal even in areas of beating muscle. Previous work by Jin et al. found that including the CMV enhancer in front of the $250 \mathrm{bp}$ promoter piece increased expression levels, but slightly decreased specificity in vivo (Jin et al., 1995). In mouse ES cells the CMV enhancer in front of the $2.1 \mathrm{~kb}$ promoter fragment results in a higher percentage of GFP positive cardiomyocytes in a particular aggregate of beating muscle (Müller etal., 2000). Once the CMV enhancer was placed directly 5 'of the MLC-2v 250 bp promoter, GFP expression could be seen in areas of beating muscle in $\mathrm{P} 19$ Clone 6 cells. 

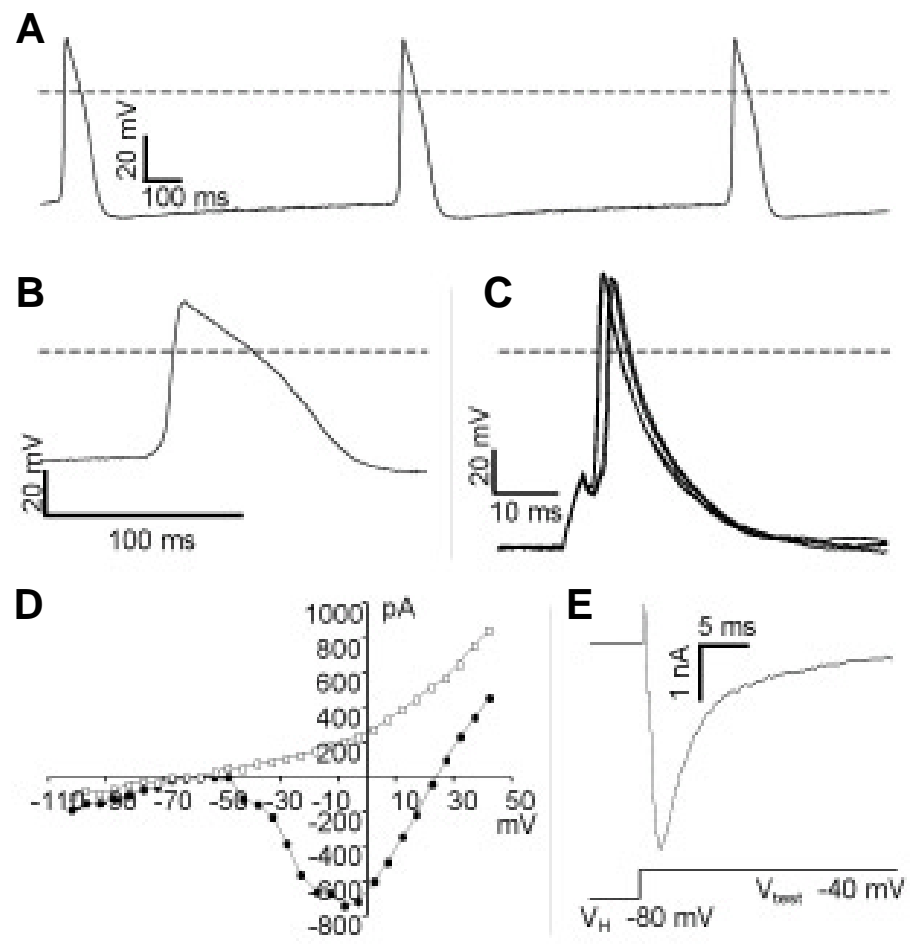

As expected the MLC-2v reporter activity described here is mostly limited to cardiomyocytes, as determined by GFP coexpression with other cardiac specific markers. We used immunofluorescence to examine the co-expression of GFP and $\alpha$-actinin in cultures that were undifferentiated, grown for 1 day after the initial 4 days of aggregation in DMSO (day 5 ) and on day 8 . In these cultures, we found that GFP is present in cells also expressing $\alpha$ actinin. Using FACS we showed that only $6 \%$ of the GFP positive cells were not positive for the cardiac specific marker tropomyosin. This provides more evidence that the GFP expression is restricted to differentiating cardiomyocytes. Although approximately $71 \%$ of the cells contained tropomyosin and only about $33 \%$ expressed GFP, this is expected because the MLC-2v promoter will only drive GFP expression in ventricular cells, while tropomyosin should be expressed in all cardiac cells in the heart (Lin et al., 1985; Franz et al., 1997). Although tropomyosin effectively identifies P19Clone6 cardiomyocytes, the disadvantage of using it in place of MLC-2v driven GFP expression lies in the fact that it is an intracellular protein thus is more labor intensive as an assay, and requires the cells to be fixed for staining, resulting in the loss of cardiomyocyte viability so that transplantation of cells after selection is excluded.

The ability of GFP positive cells from P19Clone6 \#1-23 to generate large action potentials with a high upstroke velocity and a short $\mathrm{APD}_{50}$ when forced to a resting membrane potential of $-80 \mathrm{mV}$, is explained by the substantial $\mathrm{Na}^{+}$-currents recorded under the proper voltage clamp conditions. These are features typical of mouse ventricular cells and are reminiscent of adult cells; similar measurements on a random population of cardiomyocytes from P19 cells do not exhibit these characteristics consistently suggesting that GFP marks an homogeneous subpopulation of cardiomyocytes. The low membrane potentials and spontaneous electrical and mechanical activity displayed by $\mathrm{P} 19 \mathrm{Clone} 6$ \#1-23 derived cardiomyocytes can
Fig. 7. Electrophysiological characterization of $\mathrm{P} 19 \mathrm{Cl} 6$ \#1-23 derived cardiac myocytes. (A) Spontaneous action potentials. Dotted line, $0 \mathrm{mV}$ level. (B) One of the action potentials in (A) at expanded time scale, demonstrating slow upstroke velocity and long duration. (C) Superimposed action potential recordings from a P19Cl6 \#1-23 derived cardiomyocytes (day 15 of differentiation) that had been forced to a membrane potential of $-80 \mathrm{mV}$ and then stimulated with short depolarizing current pulses of $150 \mathrm{pA} / 5 \mathrm{~ms}$ at an interval of 2 seconds. Note fast upstroke and large overshoot. (D,E) Voltage clamp experiments on \#1-23 (day 15) derived cardiomyocytes at $22^{\circ} \mathrm{C}$. (D) Example of IV relationship of peak inward current ( $\bullet$, ensemble of $\mathrm{Na}^{+}$and $\mathrm{Ca}^{2+}$ currents) and steady state current ( $\boldsymbol{\square}$, mainly $\mathrm{K}^{+}$currents). Data were obtained from a cell held at $-60 \mathrm{mV}$ and then stepped through a series of test potentials ranging between $-105 \mathrm{mV}$ and $+45 \mathrm{mV}$. Note the absence of inward rectification of the steady state current at potentials more negative than $-70 \mathrm{mV}$. (E) Example of inward sodium current recorded when stepping from a holding potential of $-80 \mathrm{mV}$ to $-40 \mathrm{mV}$.

be explained by the absence of inward rectifier $\mathrm{K}^{+}$current $\left(\mathrm{I}_{\mathrm{K} 1}\right.$, the current responsible for the high membrane potential in ventricular cells is absent in these cells). These features are more typical of embryonic or nodal cells. At membrane potentials of $-60 \mathrm{mV}$ or less negative, the $\mathrm{Na}^{+}$channels are largely inactivated and do not contribute to the action potential (hence the slow upstroke velocity) as demonstrated previously (van der Heyden et al., 2003).

Another reason for choosing the MLC-2v promoter is the need for a gene that is activated relatively early in cardiac differentiation, in order to decrease the time in which it takes to complete a bioassay. As shown in the literature, MLC-2v mRNA is expressed for the first time in the ventricle of mice by day 8 of development, relatively early for a heart specific gene (O'Brien et al., 1993). In P19 cells aggregated in hanging drops MLC-2v RNA is first detected by RT-PCR 2.5 days after plating (the cells were aggregated for 3 days with DMSO prior to plating) (Anisimov etal., 2002). When P19Clone6 EC cells were aggregated for 4 days and plated, it took 8 days for MLC-2v mRNA to be detected by RT-PCR (van der Heyden et al., 2003). Previous work by our lab showed that coculture of P19 EC cells with END2 cells (an endoderm-like cell line) resulted in very efficient differentiation of $\mathrm{P} 19 \mathrm{EC}$ cells to beating muscle (Mummery et al., 1991). As expected, the reporter line lacks MLC-2v activity in undifferentiated cells, such as in the first 5 days of co-culture with END2. However on day 6, 2 days before the appearance of beating muscle, GFP expression is clearly seen in the reporter cells. In accordance with the literature \#1-23 aggregates exposed to DMSO, END2 CM and growth media, had no visible GFP expression before day 4, while between days 5 and 8, GFP expression gradually increased.

With the P19Clone6 cardiac differentiation reporter line described here future work on the pathways that induce cardiomyogenic differentiation can be explored which will hopefully lead to direct applications in the development of stem cell therapies. Of particular importance, is the experimental evidence presented here that shows that the reporter line can effectively quantify cardiomyocyte inducing factors, specifically the factor of factors present in the END2 conditioned media. Once these pathways are better understood, this assay can also be used to distinguish easily between cardiomyocyte and non-cardiomyocyte cells in a way that keeps the cells intact. In addition it will allow the selection of viable ventricular cells that require replacement following myocardial infarction. 


\section{Experimental Protocols}

\section{Promoter construction}

The promoter sequence (nucleotides 1-589) of the pEGFP-N2 vector (Accession number U57608) from Clontech (Palo Alto, Ca) was removed and the remaining vector was used as a backbone for the $250 \mathrm{bp}$ rat MLC$2 \mathrm{v}$ promoter (a gift from Dr. Marjan van Kempen) (Accession number U26708; nucleotides 1714 to 1975). The human cytomegalovirus promoter enhancer sequence $\left(\mathrm{CMV}_{\text {enh }}\right)$ (nucleotides 59 to 465 from the original pEGFP-N2 vector) was subcloned in front of the MLC-2v $250 \mathrm{bp}$ promoter. The final construct (called $250 \mathrm{bp} \mathrm{MLC-2v}$ in pEGFP-TJe) is shown in Fig. 1B.

\section{Cell culture}

All cells were grown on tissue culture treated plastics at $37^{\circ} \mathrm{C}$ with a $\mathrm{CO}_{2}$ concentration of $5 \%$. P19Clone 6 cells (a gift from Dr. Akemi HabaraOhkubo) were maintained in monolayer cultures in $\alpha$-MEM (Invitrogen; Carlsbad, Ca.) supplemented with $10 \%$ fetal calf serum from Bio-Whitaker (Verviers, Belgium). END2 cells (Mummery et al., 1991; Mummery et al., 2003), an endodermal derivative of $P 19$ that secretes mesoderm inducing cardiogenic activity for both P19 and human ES cells, were grown in DMEM/F12 (Invitrogen) and supplemented with $7.5 \%$ fetal calf serum from Bio-Whitaker.

\section{END2 conditioned media}

Contact inhibited END2 cells were grown in $5 \mathrm{~mL}$ of DMEM/F12 containing $7.5 \%$ FCS per $25 \mathrm{~cm}^{2}$. After incubation for $72 \mathrm{~h}$, the conditioned media was collected, filter sterilized and stored at $-80^{\circ} \mathrm{C}$.

\section{Differentiation}

Hanging drops containing 800 cells in a volume of $20 \mu \mathrm{L}$ were plated onto the lid of bacterial grade culture dishes and incubated at $37^{\circ} \mathrm{C}$ for 4 days (Mummery et al., 1991; Slager et al., 1993). The base of the each culture dish was filled with PBS to prevent the drops from evaporating. On the $5^{\text {th }}$ day, the aggregates were collected from the hanging drops and plated in $\alpha$-MEM growth media with $10 \%$ FCS on glass cover slips or in $\mathrm{TC}$ treated plastics. The media was then refreshed every 48 hours and the aggregates were examined every day for the presence of beating muscle.

\section{Co-culture}

END2 cells were grown to $100 \%$ confluence and treated with $10 \mu \mathrm{g} / \mathrm{mL}$ mitomycin C (Sigma; St Louis, Mo.) for 3 hours. After rinsing with PBS, the END2 cells were inoculated with $130 \mathrm{P} 19 \mathrm{Clone} 6$ cells per $\mathrm{cm}^{2}$ in $\alpha$-MEM with $10 \%$ FCS, as described previously for P19 and human ES cells (Mummery et al., 2003; Mummery et al., 1991). The plates were then incubated at $37^{\circ} \mathrm{C}$ for 4 to 6 days, allowing the aggregation of the $\mathrm{P} 19 \mathrm{Clone} 6$ cells. When the P19Clone6 aggregates had attached to the END2 cells (usually about 6 days after plating) the media was refreshed every 48 hours. Every day the cells were examined for the presence of beating muscle.

\section{Stable transfections}

The CMV enhancer/MLC-2v/GFP reporter construct was transfected into $\mathrm{P} 19 \mathrm{Clone} 6$ cells using a standard calcium phosphate protocol (Chen and Okayama, 1987; Graham and van der Eb, 1973). Approximately 18 hours after transfection, the cells were washed with PBS and fresh $\alpha$ MEM was added. Between 40 and 50 hours post-transfection, the cells were trypsinized and $1 / 25$ and $1 / 50$ of a well was transferred to $10 \mathrm{~cm}$ dishes and grown in the presence of $600 \mu \mathrm{g} / \mathrm{mL}$ Geneticin (Gibco-BRL; Carlsbad, $\mathrm{Ca}$ ). The media was refreshed every 2 days with fresh G418 and the cells were grown until individual colonies were visible (usually about 8-10 days). Individual colonies were picked and transferred to 96 well TC plates. These colonies were grown up to $80 \%$ confluence in a $9.5 \mathrm{~cm}^{2}$ plate and the frozen in $70 \% \alpha$-MEM, $10 \%$ DMSO and $20 \%$ fetal calf serum.

\section{Immunofluorescence}

Coverslips with cells attached or cell pellets were fixed in $2 \%$ paraformaldehyde/PBS $\theta$ (without $\mathrm{Ca}^{2+}$ and $\mathrm{Mg}^{2+}$ ) at room temperature for $30 \mathrm{~min}$. They were then washed 3 times with PBS and stored if necessary in PBS/ $0.01 \%$ sodium azide at $4^{\circ} \mathrm{C}$. Following fixation, the cells were permeabilized for 8 minutes at room temperature with $0.1 \%$ triton X-100 in PBS. After washing 3 more times in PBS, the cells were blocked with $4 \%$ normal goat serum/PBS at room temperature for 1 hour. The mouse monoclonal $\alpha$ actinin antibody (Sigma; St. Louis, Mo) was added in $4 \%$ NGS/PBS to a final concentration of 1:1600 and incubated at room temperature for 2 hours. The cells were then washed with $0.05 \%$ Tween/ PBS for $3 \times 10$ minutes. A

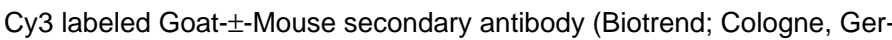
many) was added to $4 \%$ NGS/PBS to a final concentration of $1: 500$ and the cells were incubated at room temperature for 1 hour. The cells were then washed 3X10 minutes with 4\% NGS/PBS and mounted in moviol.

\section{FACS analysis}

3 plated aggregates (from 3 hanging drops) were used for each data point. Aggregates attached to TC dishes were washed once with PBS and trypsinized. Following trypsinization, the cells were washed twice with PBS and fixed in $2 \%$ paraformaldehyde/PBS at room temperature for 20 minutes. The cells were then washed twice in BSA/PBS/Azide buffer (1x PBS, $0.1 \mathrm{M}$ NaAzide, $0.5 \%$ BSA) and resuspended in $150 \mu \mathrm{L}$ permeabilization buffer ( $0.5 \%$ saponin in BSA/PBS/Azide buffer). After permeabilization at room temperature for 10 minutes, the cells were washed with PBS and resuspended in $25 \mu \mathrm{L}$ permeabilization buffer containing the monoclonal antitropomyosin antibody (clone $\mathrm{CH} 1$; Sigma; St. Louis, Mo) at a final concentration of 1:50. The cells were then incubated at room temperature for 30 minutes, followed by two washes with permeabilization buffer. Secondary antibody staining was done 1:200 in permeabilization buffer with goat antimouse phycoerythrin labeled secondary antibody (Jackson Labs; Bar Harbor, ME) for 30 minutes in the dark. The cells were then washed twice with permeabiliziation buffer, then once with BSA/PBS/Azide buffer. The cells were resuspended in $500 \mu \mathrm{L}$ BSA/PBS/Azide buffer; and analyzed on a FACSCalibur (Becton Dickinson, Franklin Lakes, NJ, USA). The BD software program CellQuest was used for data acquisition and data analysis. Green Fluorescent Protein fluorescence intensity was measured in the Fl1 channel and Phycoerythrin fluorescence intensity was measured in the $\mathrm{Fl} 2$ channel.

\section{Electrophysiological characterization of cardiomyocytes}

Standard whole-cell patch-clamp was used for recording membrane potential and currents. Patch pipette resistances were 3-5 $\mathrm{M} \Omega$ after filling with the pipette solution: $120 \mathrm{mM} \mathrm{K}$-gluconate, $10 \mathrm{mM} \mathrm{KCl,} 5 \mathrm{mM}$ HEPES, $5 \mathrm{mM}$ EGTA, $2 \mathrm{mM} \mathrm{MgCl}_{2}, 4 \mathrm{mM} \mathrm{Na}_{2}$ ATP and $0.6 \mathrm{mM} \mathrm{CaCl}_{2}$, (pH 7.2, pCa 8.0). During data recording, cultures were superfused with a salt solution consisting of: $143 \mathrm{mM} \mathrm{NaCl}, 5.4 \mathrm{mM} \mathrm{KCl}, 1.8 \mathrm{mM} \mathrm{CaCl}_{2}, 0.5 \mathrm{mM} \mathrm{MgCl}_{2}$, $0.25 \mathrm{mM} \mathrm{NaH}_{2} \mathrm{PO}_{4}, 5 \mathrm{mM}$ HEPES and $5.6 \mathrm{mM}$ glucose ( $\mathrm{pH}$ adjusted to 7.4 with $\mathrm{NaOH}$ ). The bath temperature was constant at $35-36^{\circ} \mathrm{C}$ unless specified otherwise. Voltage and current signals were recorded using an Axopatch 200B amplifier, filtered at $5 \mathrm{kHz}$, sampled at a rate of $15 \mathrm{kHz}$, stored on a Maclntosh G4 computer using custom made acquisition software (Scope) and analyzed offline with custom made software (MacDaq), kindly provided by Drs J. Zegers and A. van Ginneken (Academic Medical Centre, University of Amsterdam).

\section{Acknowledgements}

This study received financial support from Embryonic Stem Cell International (JCM and RS) and by STW grant \# MKG.5942 (MvdH)

\section{References}

ADELSTEIN, R. S. and EISENBERG, E. (1980). Regulation and kinetics of the actin-myosin-ATP interaction. Annu.Rev.Biochem. 49: 921-956.

ANISIMOV, S. V., TARASOV, K. V., TWEEDIE, D., STERN, M. D., WOBUS, A. M. and BOHELER, K. R. (2002). SAGE identification of gene transcripts with 
profiles unique to pluripotent mouse R1 embryonic stem cells. Genomics, 79 : 169-176.

BARTON, P. J. and BUCKINGHAM, M. E. (1985). The myosin alkali light chain proteins and their genes. Biochem.J. 231: 249-261.

CHEN, C. and OKAYAMA, H. (1987). High-efficiency transformation of mammalian cells by plasmid DNA. Mol.Cel/ Biol., 7 2745-2752.

EDWARDS, M.K.S., HARRIS, J.F. and MCBURNEY, M.W. (1983). Induced Muscle Differentiation in an Embryonal Carcinoma Cell Line. Mol.Cell Biol. 3: 22802286.

EMERSON, C. P., JR. and BERNSTEIN, S. I. (1987). Molecular genetics of myosin. Annu.Rev.Biochem. 56: 695-726.

FRANZ, W. M., ROTHMANN, T., FREY, N., and KATUS, H. A. (1997). Analysis of tissue-specific gene delivery by recombinant adenoviruses containing cardiacspecific promoters. Cardiovasc.Res. 35: 560-566.

GEPSTEIN, L. (2002). Derivation and potential applications of human embryonic stem cells. Circ.Res. 91: 866-876.

GRAHAM, F. L. and VAN DER EB, A. J. (1973). A new technique for the assay of infectivity of human adenovirus 5 DNA. Virology 52: 456-467.

HABARA-OHKUBO, A. (1996). Differentiation of beating cardiac muscle cells from a derivative of P19 embryonal carcinoma cells. Cell Struct.Funct. 21: 101-110.

HENDERSON, S. A., SPENCER, M., SEN, A., KUMAR, C., SIDDIQUI, M. A., and CHIEN, K. R. (1989). Structure, organization, and expression of the rat cardiac myosin light chain-2 gene. Identification of a 250-base pair fragment which confers cardiac-specific expression. J.Biol.Chem. 264: 18142-18148.

JIN, Y., PASUMARTHI, K. B., BOCK, M. E., CHEN, Y., KARDAMI, E., and CATTINI, P. A. (1995). Effect of "enhancer" sequences on ventricular myosin light chain2 promoter activity in heart muscle and nonmuscle cells. Biochem.Biophys. Res. Commun. 210: 260-266.

JONES-VILLENEUVE, E. M., MCBURNEY, M. W., ROGERS, K. A., and KALNINS, V. I. (1982). Retinoic acid induces embryonal carcinoma cells to differentiate into neurons and glial cells. J.Cell Biol. 94: 253-262.

KOLOSSOV, E., FLEISCHMANN, B. K., LIU, Q., BLOCH, W., VIATCHENKOKARPINSKI, S., MANZKE, O., JI, G. I., BOHLEN, H., ADDICKS, K., and HESCHELER, J. (1998). Functional characteritics of ES cell-derived cardiac precursor cells identified by tissue-specific expression of the green fluorescent protein. J.Cell Biol. 143: 2045-2056.

LEE, K. J., ROSS, R. S., ROCKMAN, H. A., HARRIS, A. N., O'BRIEN, T. X., VAN BILSEN, M., SHUBEITA, H. E., KANDOLF, R., BREM, G. and PRICE, J. (1992). Myosin light chain-2 luciferase transgenic mice reveal distinct regulatory programs for cardiac and skeletal muscle-specific expression of a single contractile protein gene. J.Biol.Chem. 267: 15875-15885.

LIN, J. J., CHOU, C. S., and LIN, J. L. (1985). Monoclonal antibodies against chicken tropomyosin isoforms: production, characterization, and application. Hybridoma 4: 223-242.

MCBURNEY, M. W., JONES-VILLENEUVE, E. M., EDWARDS, M. K., and ANDERSON, P. J. (1982). Control of muscle and neuronal differentiation in a cultured embryonal carcinoma cell line. Nature 299: 165-167.

MCBURNEY, M.W. and ROGERS, B.J. (1982). Isolation of Male Embryonal Carcinoma Cells and Their Chromosome Replication Patterns. Dev. Biol. 89: 503-508.

MEYER, N., JACONI, M., LANDOPOULOU, A., FORT, P. and PUCÉAT, M. (2000). A fluorescent reporter gene as a marker for ventricular specification in ESderived cardiac cells. FEBS 478: 151-158.

MÜLLER, M., FLEISCHMANN, B. K., SELBERT, S., JI, G. I., ENDL, E., MIDDELER, G., MÜLLER, O. J., SCHLENKE, P, FRESE, S., WOBUS, A. M., HESCHELER, J., KATUS, H. A., and FRANZ, W. M. (2000). Selection of ventricular-like cardiomyocytes from ES cells in vitro. FASEB 14: 2540-2548.

MUMMERY, C.L., WARD-VAN OOSTWAARD, D., DOEVENDANS, P., SPIJKER, R., VAN DEN BRINK, S., HASSINK, R., VAN DER HEYDEN, M., OPTHOF, T., PERA, M., DE LA RIVIERE, A.B., PASSIER, R. and TERTOOLEN, L. (2003). Differentiation of human embryonic stem cells to cardiomyocytes: role of coculture with visceral endoderm-like cells. Circulation 107: 2733-2740.
MUMMERY, C.L., VAN ACHTERBERG, T.A.E., VAN DEN EIJNDEN-VAN RAAIJ, A., JANNY M., VAN HAASTER, L., WILLEMSE, A., DE LAAT, S.W. and PIERSMA, A.H. (1991). Visceral-endoderm-like cell lines induce differentiation of murine P19 embryonal carcinoma cells. Differentiation 46: 51-60.

O'BRIEN, T. X., LEE, K. J., and CHIEN, K. R. (1993). Positional specification of ventricular myosin light chain 2 expression in the primitive murine heart tube. Proc.Natl.Acad.Sci. USA 90: 5157-5161.

PAQUIN, J., DANALACHE, B.A., JANKOWSKI, M., MCCANN, S.M. and GUTKOWSKA, J. (2002). Oxytocin induces differentiation of P19 embryonic stem cells to cardiomyocytes. Proc.Natl.Acad.Sci.USA 99: 9550-9555.

PASSIER, R. and MUMMERY, C. (2003). Origin and use of embryonic and adult stem cells in differentiation and tissue repair. Cardiovasc. Res. 58: 324-335.

REUBINOFF, B. E., PERA, M. F., FONG, C. Y., TROUNSON, A., and BONGSO, A. (2000). Embryonic stem cell lines from human blastocysts: somatic differentiation in vitro. Nat.Biotechnol. 18: 399-404.

ROSS, R. S., NAVANKASATTUSAS, S., HARVEY, R. P., and CHIEN, K. R. (1996). An HF-1a/HF-1b/MEF-2 combinatorial element confers cardiac ventricular specificity and established an anterior-posterior gradient of expression. Deve/opment 122: 1799-1809.

ROSSANT, J. and MCBURNEY, M. W. (1982). The developmental potential of a euploid male teratocarcinoma cell line after blastocyst injection. J.Embryol.Exp.Morpho/70: 99-112.

SKERJANC, I.S., PETROPOULOS, H., RIDGEWAY, A.G. and WILTON, S. (1998). Myocyte enhancer factor $2 \mathrm{C}$ and Nkx2-5 up-regulate each other's expression and initiate cardiomyogenesis in P19 cells. J.Biol.Chem. 273: 34904-34910.

SLAGER, H. G., VAN INZEN, W., FREUND, E., VAN DEN EIJNDEN-VAN RAAIJ AJ, and MUMMERY, C. L. (1993). Transforming growth factor-beta in the early mouse embryo: implications for the regulation of muscle formation and implantation. Dev. Genet. 14: 212-224.

THOMSON, J. A., ITSKOVITZ-ELDOR, J., SHAPIRO, S. S., WAKNITZ, M. A., SWIERGIEL, J. J., MARSHALL, V. S., and JONES, J. M. (1998). Embryonic stem cell lines derived from human blastocysts. Science 282: 1145-1147.

VAN DER HEYDEN, M. A. and DEFIZE, L. H. (2003). Twenty one years of P19 cells: what an embryonal carcinoma cell line taught us about cardiomyocyte differentiation. Cardiovasc. Res. 58: 292-302.

VAN DER HEYDEN, M. A., VAN KEMPEN, M. J., TSUJI, Y., ROOK, M. B., JONGSMA, H. J., and OPTHOF, T. (2003). P19 embryonal carcinoma cells: a suitable model system for cardiac electrophysiological differentiation at the molecular and functional level. Cardiovasc. Res. 58: 410-422.

WANG, L., FENG, Z. P., KONDO, C. S., SHELDON, R. S., and DUFF, H. J. (1996). Developmental changes in the delayed rectifier $\mathrm{K}+$ channels in mouse heart. Circ.Res. 79: 79-85.

WOBUS, A. M., KAOMEI, G., SHAN, J., WELLNER, M. C., ROHWEDEL, J., JI, GUANJU, FLEISCHMANN, B., KATUS, H. A., HESCHELER, J., and FRANZ, W. M. (1997). Retinoic acid accelerates embryonic stem cell-derived cardiac differentiation and enhances development of ventricular cardiomyocytes. J.Mol.Cell Cardiol. 29: 1525-1539.

XU, C., POLICE, S., RAO, N., and CARPENTER, M. K. (2002). Characterization and enrichment of cardiomyocytes derived from human embryonic stem cells. Circ.Res. 91: 501-508.
Received: October 2003

Reviewed by Referees: November 2003

Modified by Authors and Accepted for Publication: December 2003 